\title{
IoT monitoring system for farmers
}

\author{
V. Janicek ${ }^{1}$, J. Novak ${ }^{1,}$, T. Teply, ${ }^{1}$, M.Husak ${ }^{1}$, A. Boura ${ }^{1}$ \\ ${ }^{1}$ Department of Microelectronics, FEE CTU in Prague, \\ Technická 2, Praha 6 \\ E-mail : janicev@fel.cvut.cz
}

\begin{abstract}
Anotace:
Článek se zabývá návrhem a testováním monitorovacího systému pro potřeby farmářo̊n. Systém sestává z integrovaných autonomních BLE beacon, které jsou umístěny na sledovaných objektech (v našem modelovém př́padě se jedná o skot). Tyto beacony vysílají v určených periodách svoje identifikační údaje společně s dalšími doplňkovými informacemi, které následně slouží pro provedení přesného zaměření sledovaného objektu ve sledovaném prostoru (louka, pastva, ohradník)..

This paper discusses the concept, design and testing monitoring system for the needs of farmers. The system consists of integrated autonomous BLE beacons, which are located on monitored objects (in our model case, cattle). These beacons transmit their identification data in specified periods together with other additional information, which is then used to perform the precise targeting of the monitored object in the monitored area (meadow, grazing, fence).
\end{abstract}

\section{INTRODUCTION}

The increasing globalisation of the food market also places increasing demands on accompanying services, which ensure, among other things, the efficiency of production itself, minimise the use of human power in the production process, increase the level of automation. This trend can be observed in recent years in areas that have remained on the margins of interest of application engineers for many years, such as agriculture. By applying IoT elements, many simplifications can be achieved throughout the agricultural production chain. This paper monitors the development and application of the monitoring system to cattle pastures $[1,2]$. This system works in principle on the simple monitoring of the position of individual cattle. Above this data, however, it is possible to create an analysis tool, which from the available data will be able to determine a lot of additional information such as security of cattle against theft, health monitoring, automation of feeding and water supply and much more. The system is fully autonomous, data transmission takes place wirelessly according to the required protocol at the place of deployment. Similar products can already be purchased, but their price is disadvantageous for small breeders due to the price of monitored cattle and is only paid for applications for thousands of units of monitored entities.

\section{AgriIoT SYSTEM DESIGN}

The proposed system (called AgriIoT) consists of a central concentration element (Hub) collecting data from individual transmitters (Beacon), see Fig. 1. Data collection takes place using the Bluetooth Low Energy (BLE) protocol. This principle was chosen because of the low energy intensity, because energy consumption became the most monitored parameter in the case of Beacons located on cattle bodies. If frequent recharging of integrated accumulators is necessary, the financial and time demands of the service would be disproportionately increased. Depending on the required data collection interval, it is possible to adapt the battery size to the available space for integration into the bovine body. This tradeoff between the available space and the size of the battery deployed predetermins overall system efficiency and durability.

Individual Beacons are monitored by collection points (Hub), of which several are placed after grazing, again according to the shape and planar profile of the monitored plot. After processing in the Hub, the data is sent via the GSM or LoRa network to the central server, where the data is further processed.

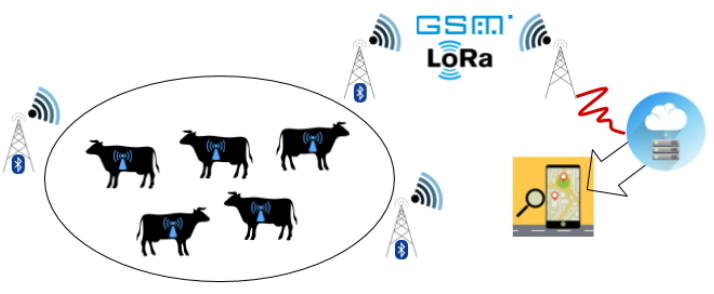

Figure 1: Principle of the e-Cattle system

\section{FUNCTIONAL SYSTEM BLOCK}

The system is made up of a chain, see Fig. 2. The information shall be transferred gradually from the monitored bovine animals to the central data warehouse. It starts with the body of cattle and the integrated Beacon, which sends data through BLE protocol to the pasture area. This signal is intercepted 
in the vicinity of the located collection hubs, which, after processing and possible encoding of the collected information, send it via GSM or similar Long-Distance networks to the central server, where the received information is decoded and further processed. The results shall be provided to the owner of the monitored bovine animals, who shall use them for his needs. The main application outputs required in most cases include protection of cattle against theft, monitoring the movement of cattle in the pasture to optimise the size of the pasture and possible alternative uses, monitoring cattle loaping and identifying areas with the highest concentration of cattle due to the adjustment of the number of feeders and water feeders, monitoring of cattle clumping and social behaviour, monitoring of pregnant animals and lambs, optimisation of feed and water on feeders and feeders, searching for a specific piece of cattle, etc.

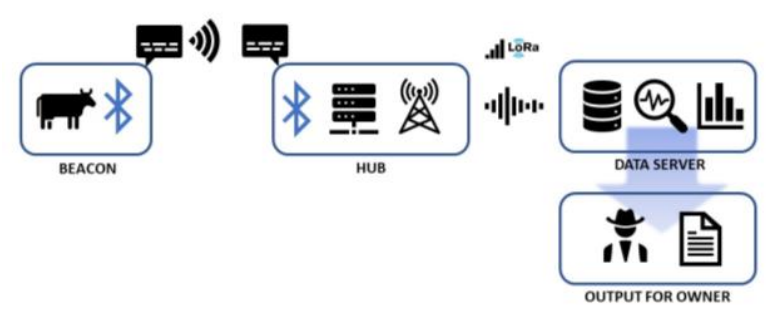

Figure 2: Functional sytem block of the AgriIoT system

\section{HARDWARE IMPLEMENTATION}

Beacon and Hub are based on the ESP32 single-chip module platform, which is a series of low-cost, lowpower system on a chip microcontrollers with integrated $\mathrm{Wi}-\mathrm{Fi}$ and dual-mode Bluetooth. The ESP32 series employs a Tensilica Xtensa LX6 microprocessor in dual-core and includes built-in antenna switches, RF balun, power amplifier, lownoise receive amplifier, filters, and powermanagement modules. ESP32 is created by Espressif Systems [3]. It is a successor to the ESP8266 microcontroller. Beacon (see Fig. 3a) is powered by a LiPol battery with a capacity of $10 \mathrm{Ah}$, both parts are inserted into a waterproof housing, which is connected to the neck of the animal by a leather belt, see Figure 3b. The ESP32 Wemos MiniD1 module also includes a battery charger that controls the USB charging process. The detail of the case is shown in Fig. 3c.
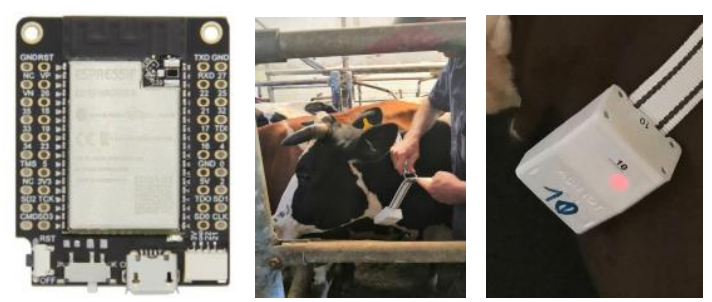

Figure 3: a) ESP32 modul for Beacon, b) applied beacon on the cattle, c) beacon package

The Hub uses the LilyGO TTGO T-Call V1.3 kit (Fig. 4a), which integrates the GPRS modem and battery charger with the ESP32 module. This single PCB connection simplifies the complexity of wiring and increases reliability. The module is powered by a LiPol battery with a capacity of $30 \mathrm{Ah}$. The battery pack is placed in a waterproof installation box (see Fig. 4b). Figure 4c shows the internal arrangement of the installation box with hub and accumulator.
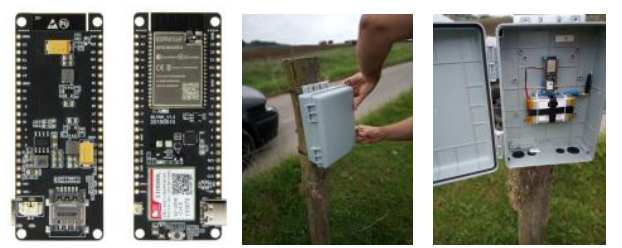

Figure 4: a) ESP32 T-Call modul for Hub, b) installation box c) internals of Hub

\section{SOFTWARE}

The utility software was created in the Arduino IDE, which, after installing support, allows programming of modules with ESP32. The flowchart of the Beacon utility software is shown in Fig. 5a. After initialization of the module, the beacon name is sent via BLE protocol and information about the battery charge rate is sent every 24 hours. This information is broadcast at $200 \mathrm{~ms}$, then the whole system is put into sleep mode for 60 seconds. After waking up, the whole process repeats. After initial initialization, the Hub (see Fig. 5b) follows this timeline and scans its surroundings every 5 minutes for 70 seconds. At this interval, the identification of each beacon should be sent. At the end of the scanning cycle, the current capacity of the battery is detected. Subsequently, the GPRS modem (which consumes the most power in the entire hub chain) is initialized, contact with the data server is made and all the collected data is sent. The Hub sends MAC addresses and names of all detected

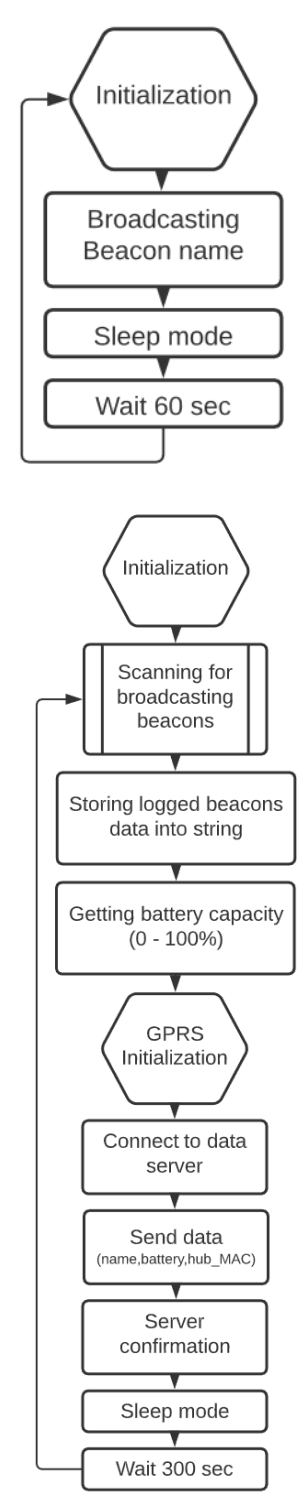

Figure 5:Software development diagram beacon(a) and hub(b) 
beacons sequentially, then the battery capacity $(0,25$, $50,100 \%)$, the checksum of the detected beacons and the MAC address of the hub. This information is processed on the server. So far, no encoding of the information being sent is deployed in the pilot operation. By setting beacon scanning time and the length of the sleep status (see Fig. 6), it is possible to choose a trade-off between repeating scanning and saving energy, which is very important for beacons, as mentioned earlier.

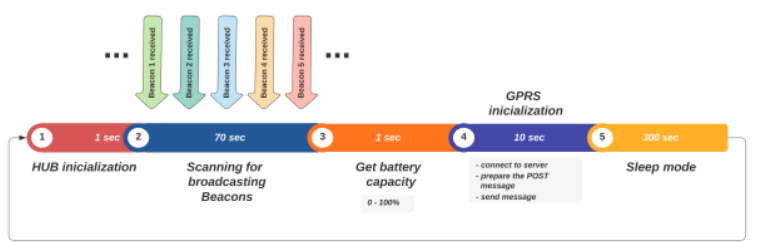

Figure 6: Time diagram for process flow of the AgrIoT system

\section{SYSTEM PILOT TEST}

An agricultural farm in Krhenice near Prague was selected for the pilot project. A total of 30 beacons and 9 hubs were installed. All beacons were strapped to the necks of selected cattle after the internal battery was charged. The collection hubs have been placed around the perimeter of the pasture so that the internal antennae cover as much of the pasture as possible with their receiving diagrams. For later purposes of precise targeting of a particular piece, it was necessary to ensure that at least 3 hubs were covered at any place in the pasture, so that triangulation could be performed, as is the case with GPS. The location is shown in Fig. 7.

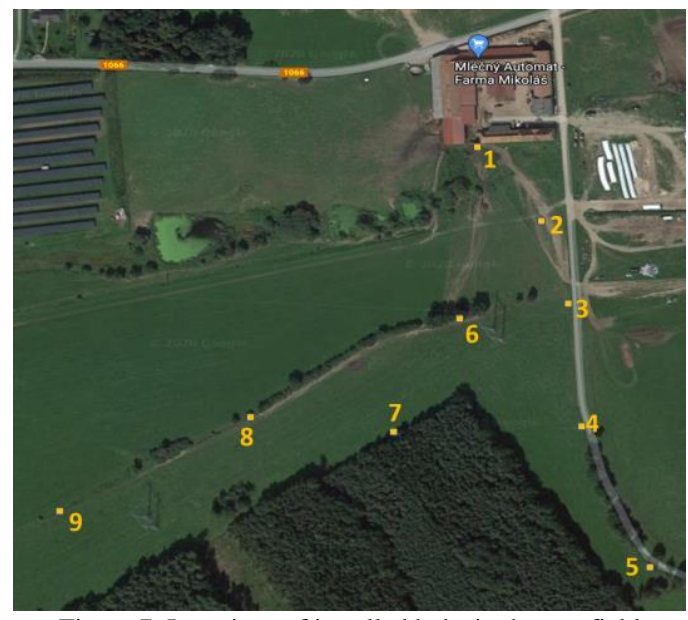

Figure 7: Locations of installed hubs in the test field

During the test operation, regular data collection from hubs was carried out. Every day, an evaluation of the number of detected beacons was carried out in relation to the position of the hub. The next step is the deployment of an analysis tool for triangulation of a particular piece of cattle in pasture for the purpose of optimizing feed and water distribution. In cooperation with the project partner, the process of modifying the software is a hub that secures the entire communication by encryption, crypts the detected beacon addresses and adds additional information that eliminates the possibilities of infiltration from the outside. This version of the software will be deployed with hubs in the environment of breeding large numbers of cattle in the order of tens of thousands of pieces.

\section{CONCLUSIONS}

So far, the test mode has brought a lot of information about optimizing the range of the sensing capabilities of the hub (depending on the position of the antenna), battery life depending on the desired interval of sending data to the central server, the influence of beacon position on the body of the monitored object, mutual position of the hubs and much more. Interest in this monitoring system has come from the needs of South American customers, who, with the increasing number of cattle and meat prices on the market, are also beginning to optimize the inputs that can be influenced.

\section{ACKNOWLEDGEMENT}

This work has been supported by the Technology Agency of the Czech Republic under the DELTA support programme for applied research, experimental development and innovation No. TF06000066 and partially by the EU projects (Energy for Smart Objects (EnSO), No. 692482-2, Wide band gap Innovative $\mathrm{SiC}$ for Advanced Power (WInSiC4AP), No. 737483), project of Technology Agency of the Czech Republic No. TH03010205 MEMS sensors with optical scanning (MEMS-ESO) and by Smart Access Control for Smart Buildings (SACON), No. 12708.

\section{REFERENCES}

[1] Unold O. et al. (2020) IoT-Based Cow Health Monitoring System. In: Krzhizhanovskaya V. et al. (eds) Computational Science - ICCS 2020. ICCS 2020. Lecture Notes in Computer Science, vol 12141. Springer, Cham. https://doi.org/10.1007/978-3-030-50426-7_26

[2] Thakur B.S., Sheetlani J. (2021) Analyzing a Cattle Health Monitoring System Using IoT and Its Challenges in Smart Agriculture. In: Satapathy S., et all(eds) Intelligent System Design. Advances in Intelligent Systems and Computing, vol 1171. Springer, Singapore. https://doi.org/10.1007/978-981-15-5400-1_79

[3] ESP32 datasheet. https://espressif.com/en/products/hardware/esp3 2/overview 